\title{
Proceedings of the 117th Meeting of the Society of British Neurological Surgeons held jointly with the Polish Neurosurgical Society, Warsaw and Katowice, Poland, 23-26 September 1990
}

DELAYED VASOSPASM AFTER SAH IS ASSOCIATED WITH INHIBITION OF EDRF ACTIVITY

JV Byrne, DH Edwards, TM Griffiths, BA Bell. Atkinson Morley's Hospital, London and University Hospital of Wales, Cardiff

Haemoglobin $(\mathrm{Hb})$ has been implicated in the genesis of cerebral vasospasm after subarachnoid haemorrhage because its release from periarterial clot coincides with the maximum incidence of delayed spasm. It inhibits the potent endogenous nitrovasodilator endothelium-derived relaxation factor (EDRF). Endothelium dependent relaxation is associated with increased levels of cyclic GMP in arterial smooth muscle. The authors used cyclic GMP assays as a means of quantifying EDRF activity in cerebral vessels exposed to $\mathrm{Hb}$ in vitro and after simulated subarachnoid haemorrhage.

Intraluminal or adventitial exposure to $\mathrm{Hb}$ caused reversible depression of basal cyclic GMP levels in isolated pig cerebral arteries. Cyclic GMP assays of pig cerebral arteries were performed two and seven days after simulated subarachnoid haemorrhage by intrathecal injections of purified $\mathrm{Hb}$ or whole blood. Basal cyclic GMP levels were normal in vessels examined after two days, but depressed in vessels from animals treated with whole blood at seven days. In the latter group no further depression of the cyclic GMP level could be induced by in vitro exposure to $\mathrm{Hb}$.

The data support the contention that adventitial exposure to $\mathrm{Hb}$ inhibits basal EDRF activity and demonstrated an irreversible reduction in basal cyclic GMP levels after prolonged exposure to whole blood in vivo. Both mechanisms could contribute to delayed vasospasm after SAH.

ANTERIOR MIDLINE ANEURYSMS VIA A TREPHINE APPROACH

AJ Keogh. Preston

An interhemispheric approach to anteriorly placed cerebral aneurysms has been advocated for some years and is felt to be the safest and most effective.' A bifrontal craniotomy with division of the superior sagittal sinus is usually utilised. This extensive procedure, formidable in the fragile or elderly, may be unnecessary. A frontal trephine approach was carried out in 50 consecutive patients. There was an equal sex distribution in the series with a mean age at surgery of 48 years $(28 \%$ were 60 years of age or over). Definitive treatment was possible in all patients, with no operative mortality and an acceptable morbidity.

The results support an initial impression ${ }^{2}$ that adequate exposure and the best anatomical orientation are achieved with this simplified interhemispheric approach.

1 Susuki J, Mizoi K, Yoshimoto T. J Neurosurg 1986;64:183-90.

2 Keogh AJ. Brit J of Neurosurg 1990;4:337-38.
POSTERIOR CEREBRAL ARTERY ANEURYSMS-A DIFFERENT APPROACH

CJ Gerber, G Neil-Dwyer. Southampton

Posterior cerebral artery (PCA) aneurysms are uncommon. They constitute $5 \%$ of posterior circulation aneurysms.' Surgical experience of their treatment is therefore limited. PCA aneurysms are usually approached by either the pterional approach ${ }^{2}$ or subtemporally,' depending on their location.

The experience in the Wessex Neurological Centre since 1964 was reported of 14 PCA aneurysms especially with regard to radiological diagnosis and the planning of the surgical approach. The transzygomatic approach to proximally placed $P_{1}$ and $P_{2}$ aneurysms was presented.

1 Drake CG. Prog Neurol Surg 1978;9:122-94. 2 Yasargil MG, Antic J, Laciga R, et al. Surg Neurol 1976;6:83-91.

ACUTE INTRACEREBRAL HAEMORRHAGE: REAPPRAISAL OF MANAGEMENT

RM Redfern, MM Sharr. Brook Hospital, London

The prognosis for patients in coma from spontaneous intracerebral haemorrhage is poor. To identify those who might benefit from emergency surgery a policy was adopted whereby all comatose patients referred with a history suggesting spontaneous intracranial haemorrhage had urgent clinical and radiological assessment, with a view to clot evacuation. Sixteen patients had emergency surgery, of whom eight had underlying aneurysms and eight had miscellaneous causes. CT scan appearances suggesting an aneurysm led to angiography being performed in six patients in four of whom aneurysms were demonstrated; in other cases, even when CT suggested an aneurysm, if it was felt that further delay would lead to a fatal outcome, haematoma evacuation and, if identified, clipping of the aneurysm was undertaken without angiography. At one year the Glasgow Outcome Score (GOS) in the aneurysm group was I/II (5), III (1), and V (1), the eighth patient having a GOS of II at three months; outcome in the miscellaneous group was GOS II (1), III (2) and V (5). Urgent evacuation of life-threatening intracerebral haematomas due to aneurysms, and clipping of the underlying aneurysm, even without preoperative angiography, may be beneficial in a number of cases.

"DESIGNER" OSTEOTOMY FOR APPROACHES TO LESIONS OF THE SKULL BASE

G Neil-Dwyer, PD Lees, BT Evans, H Davies. Southampton

The orbit can be treated as an osteoplastic structure; with the exception of the delicate bones of the floor and medial wall, osteotomies can be performed on the remaining orbital skeleton to allow significantly improved access to the orbital and intracranial contents and especially the skull base.

Using a variety of orbital osteotomies in conjunction with craniotomy the authors were able to plan the surgical approach to a number of skull base lesions gaining excellent access with a minimum of brain retraction. This approach was useful in lesions in the supra, para, and retrosellar regions including both the interpeduncular fossa and the petrous ridge.

The visual, cosmetic and neurological results were presented of the first 25 patients with a variety of pathological lesions.

INITIAL EXPERIENCE WITH THE COSMANROBERTS-WELLS STEREOTACTIC SYSTEM MF Pell, DGT Thomas. National Hospital, London

The Cosman-Roberts-Wells stereotactic instrument is a recently developed modification, based on an arc-radius design, of the BrownRoberts-Wells stereotactic frame utilising the existing fixation and fiducial components of the Brown-Roberts-Wells stereotactic system to localise and verify target data. The design modification have been made with a view to facilitating technical approaches both in stereotactic biopsy and in stereotactic craniotomy, whilst addressing the same stereotactic space. Over a two month period, 25 procedures were performed which included 19 stereotactic biopsy procedures, two CT guided stereotactic craniotomies, two stereotactic placements of Bennett Ball for thalamotomy, one stereotactic implantation of intracranial electrodes for recording in drug resistant epilepsy and one aspiration of cyst. In all cases successful targeting was achieved. There were no complications related to operation in this series. This frame offers rapid targeting without the need to predetermine entry points, as well as allowing direct lateral passes and unimpeded stereotactic craniotomy.

SPINAL OSTEOMYELITIS: THE NEED FOR A DIVERSE APPROACH

$S$ Chatterjee, $P$ Brownson, $R$ White, $T$ Green, G Findlay. Liverpool

Spinal osteomyelitis and infections of the spinal canal remain uncommon and, with the exception of TB, there are few large clinical series. With the reduced incidence of TB in the UK, the nature of spinal infection has significantly changed in the last quarter of the century.

In the last five years, the authors encountered 38 cases of spinal infection unrelated to spinal instrumentation with a very variable clinical presentation ranging from persistent back pain and root symptoms to kyphotic deformities and subdural abscesses. Staph aureus was the commonest organism isolated but a wide range of other organisms were also 
identified. The primary source of infection remained undetectable in the majority of cases.

The basic goals of treatment were to allow neurological recovery, relieve pain and produce spinal stability. The methods of management varied considerably ranging from purely conservative management in certain cases to radical anterior approaches for debridement and internal stabilisation of the spine.

The clinical and bacteriological features of these 38 cases were presented in detail. Emphasis was placed on the differing types of conservative and surgical strategies which are required in the management of these conditions.

THE USE OF CRANIOTOMY UNDER LOCAL ANAESTHESIA TO PERMIT MAXIMUM RESECTION OF LOW GRADE GLIOMAS

H Marsh, R Walsh, R Schmidt. Atkinson Morley's Hospital, London

Surgical excision of gliomas in eloquent areas of the brain is always limited by fear of inflicting a neurological deficit. With malignant gliomas a limited resection of the tumour does not matter very much in that the prognosis is very poor however radical the surgery. With low grade gliomas it is difficult to prove that a radical resection improves survival but there is some suggestive evidence. The increasing availability of CT scanning means that neurosurgeons now see many patients with low grade gliomas whose only presenting complaint is epilepsy. The lack of a focal deficit in these patients increases the surgeon's anxiety about producing a deficit and will often mean that only a very limited resection of the tumour will be performed. The authors had started carrying out such operations under local anaesthetic. Cortical mapping was combined with constant neurological examination of the patient while resecting the tumour and multiple smear biopsies to define tumour margins. This permits maximum tumour resection with minimum risk of producing a focal deficit. The results for the first seven patients treated in this way were presented. The procedure was remarkably simple and much better tolerated by the patients than expected. If maximum tumour resection is considered to be the best policy for these tumours the authors recommended that all such operations should be carried out in this way if there is any risk of damage to eloquent areas of the brain.

\section{PHOTODYNAMIC THERAPY OF RECURRENT CEREBRAL GLIOMA}

G Brocklehurst. Hull

Seventeen patients with recurrent malignant cerebral gliomas following previous treatment were sensitised with Haematoporphyrin derivative (HPD) $2.5 \mathrm{mgm} / \mathrm{kg}$. Forty eight hours later the tumour was reexcised using standard neurosurgical laser technique. Red light at $632 \mathrm{~nm}$ wavelength (from a copper vapour dye-laser) was then applied to the cavity using a delivery system in which the fiberoptic tip was surrounded by a rubber balloon filled with "intralipid". Intra-operative temperature monitoring and post-operative ICP monitoring was accompanied by nursing with protection from direct light for two weeks. All patients have subsequently died from recurrent glioma. Average survival time was about six months, with minimal biological affects from therapy and no significant prolongation of life. The technique proved feasible without significant complications, and may warrant a controlled trial in the primary treatment of malignant gliomas.

IMPORTANT PROGNOSTIC VARIABLES IN GLIOBLASTOMA MULTIFORME

TJD Pigott, JS Lowe, J Palmer. Nottingham

A total of 77 specimens of glioblastoma were analysed for the expression of the nuclear proliferation antigen $\mathrm{Ki}-67$ and a proliferation index calculated. This was then correlated with survival, and with other factors such as patient age, tumour site, preoperative neurological status, and radiotherapy previously reported as being important in the determination of prognosis. Relative youth, frontal tumour site and treatment with external beam radiation had an important positive influence on survival. The statistical analysis would suggest that for every five years of increasing age the survival is reduced by one month, and that postoperative radiotherapy confers an average of three months extra survival. The preoperative Karnovsky score and the presence of necrosis were not related to outcome. This would suggest that tumours with no necrosis but very deranged nuclear morphology may be classified as glioblastoma and not anaplastic astrocytoma.

Despite the attractive hypothesis that rapidly proliferating tumours might be associated with a worse prognosis compared to slowly proliferating lesions, the $\mathrm{Ki}-67$ index in this large series offered no prognostic information even when individual sites were considered separately.

HAVE THERE BEEN SIGNIFICANT IMPROVEMENTS IN SURVIVAL FROM CHILDHOOD BRAIN TUMOURS?

R Kumar, V Blair, N Patel, RA Cowie. Manchester

There have been significant improvements in survival from childhood cancer, but for children with brain tumours the results are not so spectacular. The study was undertaken to determine the factors contributing to the improvements. Over 800 children with brain tumours were registered in the Manchester Children's Tumour Registry in the period 1954-87. The study group of 355 of these children consisted of those with either juvenile astrocytoma of the cerebellum, medulloblastoma, or ependymoma. The follow up period was from two to 30 years.

The ready availability of CT since 1977 provided a swift and non-invasive means of diagnosis of these tumours. This period also coincided with the use of chemotherapeutic protocols for brain tumours and the refinements in radiotherapy. Thus those who were diagnosed before 1977 were classed as in preCT era and those after 1977 as in the CT era.

The ability to diagnose these tumours in life rose considerably in the CT era compared with the pre-CT era $(p=0.02)$. The diagnosis of hydrocephalus was also improved leading to a higher number of CSF shunt operations ( $p>0.001)$. Operative mortality in the latter period was only $8 \%$ compared with the pre-CT era of $15 \%$. The early management mortality at one year also improved considerably from $56 \%$ in the preCT era to $28 \%$ in the CT era $(p=0.01)$. There was no statistical difference in the long term (up to 10 years) survival for juvenile astrocytoma of the cerebellum, or for ependymoma. For children with medulloblastoma, the five year survival was $34 \%$ in the pre-CT era and $50 \%$ in the CT era ( $p=0.0269$ ). This was reduced to $24 \%$ and $31 \%$ in the two groups respectively $(p=0.297)$ at 10 years: however, the numbers at risk were very small at 10 years in the CT era.

Although there is some improvement in short term survival, on prolonged follow up there does not appear to be any significant difference in survival in children with juvenile astrocytoma of the cerebellum and ependymoma. For medulloblastoma, there is a significant difference at five years.

SUPEROMEDIAL ORBITAL MARGIN REMOVAL IN THE CORRECTION OF SINCIPITAL

ENCEPHALOCELE

OC Sparrow, GE Lello, R Gopal. London, Manchester, and South Africa

Meningoencephalocoeles situated at the sinciput represent a meningocerebral hernia through the foramen caecum and out via the facial skeleton. Surgical correction is complicated by both difficulties in adequately closing the dural and bony defects in the cranial base, and in correcting the secondary facial deformities. The later the repair is performed, the more severe the secondary changes due to distortion of facial growth have become, necessitating complex procedures.

Early total corrective surgery has been proposed, but rarely reported. ${ }^{1}$ A simple procedure suitable for use in young children is described, ${ }^{2}$ comprising removal of the superomedial orbital margin for access to the defect in the cranial base and allowing avoidance of a formal craniotomy without compromising craniofacial correction of the less severe deformity seen in these children. A modification of the procedure may also be used for more extensive surgery involving correction of hypertelorism in the older patient. Here a similar improvement in access aids repair of the cranial basal dural and bony defects, though a bifrontal craniotomy has seemed unavoidable to permit orbital mobilisation.

1 David DJ, Sheffield L, Simpson D, White J. Br J Plastic Surg 1984;37:271-84.

2 Lello GE, Sparrow OC, Gopal R. J CranioMax-Fac Surg 1989;17:293-8.

\section{PRIMARY SPINAL PRESENTATION OF NON} HODGKINS LYMPHOMA. A REAPPRAISAL OF MANAGEMENT AND PROGNOSIS

R Laing, J Jakubowski, B Hancock. Sheffield

Primary presentation of non Hodgkins lymphoma (NHL) as spinal extradural compression is rare. It has been traditionally considered that NHL presenting in this way has a much more favourable prognosis than other extradural malignancies, thus prompting aggressive surgical management. In this way treatment differs from spinal compression arising in patients with established NHL where radiotherapy and chemotherapy alone is the method of choice. There were thirteen patients with NHL presenting as spinal extradural compression out of a total of 1500 new cases of NHL diagnosed in Sheffield between 1979-89. In the same period 312 
cases with spinal extradural malignant compression were operated on in this department.

The patients with NHL were predominantly late middle age and elderly. Seven patients were aged between 54 and 70 , five were over 79 and one aged 22. There were nine men and four women.

Standard treatment comprised decompressive laminectomy with postoperative radiotherapy. Chemotherapy was given if staging investigations were positive. Five patients proved to be stage four (disseminated disease) and there were eleven B-cell and two T-cell lymphomas.

None of the patients deteriorated neurologically following the surgery. All patients over 65 years old (6) died within four months due to the complications related to a combination of surgery and DXT. All patients who survived four months (7) subsequently developed disseminated disease whether or not they appeared to have localised disease at presentation. Two patients are still alive three and eleven years after diagnosis $(15 \%)$. The rest died within two years.

To improve the outcome of treatment the authors believed that laminectomy is best avoided in the elderly group and one should rely on dexamethasone and DXT alone as these patients are frequently debilitated and are prone to postoperative complications. Operation may be required in the younger patient with rapidly progressing paralysis and/or when satisfactory histological material cannot be obtained by less invasive methods, ideally radiologically directed core biopsy. Taking into consideration the fact that all younger patients who survived the initial postoperative period subsequently manifested disseminated disease, the authors suggested that treatment with steroids and radical local radiotherapy should be combined with chemotherapy irrespective of the results of staging investigations.

\section{POST LAMINECTOMY DEFORMITY}

\section{G Findlay. Liverpool}

The problem of spinal deformity following laminectomy in the presence of anterior spinal disease has been recognised for decades in infection and more recently in metastatic disease. However, the occurrence of deformity following laminectomy in the otherwise intact spine has been largely ignored. Although a rare occurrence in adults unless bilateral fascetectomy has also been performed, it is a common sequel of laminectomy in children.

There is an extensive literature documenting the occurrence of post-laminectomy deformity. The area of greatest risk is in laminectomy of the cervical spine. Three cases where post laminectomy deformity occurred despite measures to prevent it were discussed in detail.

For the last five years all cases having cervical or upper thoracic laminectomy performed in children had been supplemented by simultaneous inter transverse fusion with encouraging results. The problems of the treatment of the established deformity were discussed, together with possible future developments in prevention such as laminoplasty, and tension banding.

THE SCOPE OF NEUROSURGERY IN THE ELDERLY RS Maurice-Williams. Royal Free Hospital, London

There is a paucity of literature on the subject of neurosurgery in elderly patients. Of 1000 consecutive neurosurgical operatons, $15 \cdot 2 \%$ were on patients aged $65-74,7 \cdot 5 \%$ on those aged $75-84$, and $0.4 \%$ on patients of 85 or more. This represents a disproportionate number in the 65-74 age group compared with the general population. Of operations on those of 65 plus, $25 \%$ were for intracranial were for the effects of trauma, and $14 \%$ were for ventricular shunts.

All patients operated on over a 13 year period were analysed. $15.6 \%$ of the population is aged 65 or more. The following conditions were over represented: intracranial meningiomas $(35 \%$ of the total with this condition), chronic subdural collection $(65 \%)$, spinal extradural tumours $(37 \%)$, spondylotic myelopathy $(49 \%)$ and lumbar canal stenosis ( $41 \%)$. Under represented conditions included aneurysms (4\%), lumbar disc protrusions $(3 \%)$, compound depressed skull fractures $(1 \%)$

Age appears to have little or no effect on the outcome of neurosurgery unless there is a serious intercurrent disease or a general disturbance of the nervous system such as after a head injury or subarachnoid haemorrhage. Age alone should not bar the consideration of major surgery to the brain or spine.

PROPHYLACTIC ANTICOAGULATION IN NEUROSURGICAL PRACTICE

N Garvan, K Mythili, M Tariq, K Rasheed. Romford

The incidence of deep venous thrombosis and pulmonary embolism in neurosurgical practice is poorly defined. Pulmonary embolism was the cause of death in three young patients who had surgery for craniopharyngioma, recurrent oligodendroglioma and intraventricular low grade glioma, respectively. Following this it was felt that further preventative measures should be tried along with the pneumatic leggings used during surgery. Reports from other specialties have shown that low dose Heparin can reduce the incidence of these complications without an increase in problems with haemorrhage. Low dose Heparin was used extensively in nonintracranial neurosurgical practice without any obvious increase or difficulty with haemorrhage. Since then it has been used in 60 patients undergoing intracranial procedures and the authors were satisfied with its safety.

THE EFFECT OF TAMOXIFEN (TAM) ON THE STILBOESTROI INDUCED ANTERIOR PITUITARY TUMOUR IN FISHER RATS

A Stawowy, A Kemeny, J Jakubowski. Lodz, Poland, and Sheffield

Tamoxifen (TAM) is a mixed oestrogen agonist-antagonist and is best known for its tumours, $35 \%$ were for spinal disorders, $15 \%$

use in the management of human breast cancer. Its activity depends on the level of oestrogen present when administered. $\mathrm{Re}$ cently it has been reported that it enhances the effects of bromocriptine and inhibits growth of experimental tumours. Its use in the treatment of human prolactinomas was suggested. Anterior pituitary tumours were induced in female Fisher F344 rats by implanted silicone capsules containing stilboestrol. After a 10 week period the animals were treated with TAM $1 \mathrm{mg} / \mathrm{kg}$ per day for a period of one week.

In earlier work it was shown that the bloodflow in the anterior pituitary decreased by $35 \%$ after single IV doses of TAM but $\mathrm{CBF}$ and $\mathrm{BP}$ remained unchanged. Prolonged TAM administration over a period of one week had no such effect. There are reports in the literature that TAM inhibits growth of the animal experimental pituitary tumour. However, such inhibition was found when Tamoxifen was given at the onset of induction of the tumour. In this study TAM was given after adenomatous change was established (more resembling the clinical situation). No inhibition but enhancement of the growth and increase of vascular supply was observed. Finally it appears that TAM changes the bloodflow in the adenohypophysis in the female rat and the direction of change is dependent on whether there is a high or low oestrogen state.

THE ANTICIPATION OF POST-TRAUMATIC INTRACRANIAL HYPERTENSION

DJ Price, $M$ Czosnyka, $M$ Williamson. Wakefield and Warsaw, Poland

In a number of British Neurosurgical Departments, the monitoring of intracranial pressure in patients with clinical and radiological features suggesting development of post-traumatic hypertension is routine. Decisions concerning repeat CT scanning, pharmacological or surgical treatment are usually made when the mean pressure has risen above pre-determined thresholds. The ICP signal does however contain additional information about both the reserve of compensatory volume within the cranio-spinal axis and the cerebrovascular stability. For a period of 10 years, continuous on-line computer analysis of ICP of head injured patients provided a linear regression of the cardiac pulse wave amplitude and the mean pressure. The gradient of this regression did prove useful as a surrogate for elastance within a mathematical model which drove an automated closed-loop Mannitol controller. The gradient did not however identify those patients with normal ICP which would later rise significantly.

With the help of software developed in Poland, the signal analysis was changed to a Fast Fourier Transform. In a review of the

\begin{tabular}{|c|c|c|c|}
\hline & Control & $\begin{array}{l}D E S+10 \\
\text { weeks }\end{array}$ & $\begin{array}{l}D E S+1 \text { week } \\
\text { of } T A M\end{array}$ \\
\hline $\begin{array}{l}\mathrm{LPBF}\left(\mathrm{ml} 100 \mathrm{~g}^{-1} \mathrm{~min}^{-1}\right) \\
\text { MPBF }(\mathrm{ml}(100 \mathrm{~g})-1 \mathrm{~min}) \\
\text { TPBF }(\mathrm{ul} / \mathrm{min}) \\
\text { Blood pressure }(\mathrm{mm} \mathrm{Hg}) \\
\text { Body weight }(\mathrm{g}) \\
\text { Weight of adenohypophysis }(\mathrm{mg}) \\
\text { Number }\end{array}$ & $\begin{array}{l}93 \cdot 2(12) \\
115 \cdot 0(11) \\
12 \cdot 7(2) \\
102 \cdot 0(16) \\
210 \cdot 0(12) \\
11 \cdot 5(3) \\
16\end{array}$ & $\begin{array}{c}24 \cdot 8(6) \\
24 \cdot 7(8) \\
18 \cdot 2(6) \\
120 \cdot 0(23) \\
117 \cdot 0(14) \\
80 \cdot 0(34) \\
8\end{array}$ & $\begin{array}{l}33 \cdot 7(4)^{\star} \\
33 \cdot 5(5)^{\star \star} \\
31 \cdot 4(7)^{\star \star} \\
136 \cdot 0(35) \\
116 \cdot 0(5) \\
95 \cdot 9(25) \\
7\end{array}$ \\
\hline
\end{tabular}

${ }^{\star} \mathrm{p}=0.05 .{ }^{\star \star} \mathrm{p}=0.01$, non-paired $t$ test compared with DES only.

Difference between control and each treatment groups all significant, $p=0.001$.

LPBF = lateral pituitary blood flow.

MPBF = medial pituitary blood flow

TPBF = total pituitary blood flow. 
last 50 head injured patients, the authors confirmed the poor predictive value of the amplitude/mean gradient but have shown that the correlation coefficient $(R)$ reflects cerebrovascular stability and sudden unexpected rises in ICP are preceded by rises in the $R$ value towards 1.0 allowing anticipatory therapy.

WHAT IS SYRINGOBULBIA?

B Williams. Smethwick

From a database of 550 cases of syringomyelia and benign hindbrain herniation 54 cases have been analysed after cranio-vertebral decompression for bulbar symptoms. Forty four patients were followed: the mean time of review after operation was 15.2 years, range 3-34. Five patients had subsequent ventriculo-atrial shunting, and three had syringopleural shunting. Analysis was presented of occipital headache, vertigo, voice disturbance, paraesthesiae, dysphagia, dysphonia, hearing difficulty, nystagmus, diplopia, facial nerve, palatal, accessory and hypoglossal weakness. Patients did well after surgery but some disappointing cases were presented in detail together with likely reasons for failure.

It was suggested that the syndromes of syringobulbia are best divided into three. The commonest is when stem symptoms are not associated with cavity formation-the cause is probably distortion of the hindbrain and nerves, plus vascular loops being pressed into the stem. Secondly, clefts may run downwards from the floor of the fourth ventricle: these are also due to cranio-spinal pressure dissociation acting across the foramen magnum. These may be present without syringomyelia. Lastly, ascending syringomyelia occurs which is an upward dissection from a cervical syrinx cavity into the tissues of the brain stem and may be due to tumorous or post-traumatic syringomyelia.

THE ANATOMY OF NEUROVASCULAR

COMPRESSION IN TRIGEMINAL NEURALGIA

PJ Hamlyn, TT King. London Hospital

Debate continues on whether neurovascular decompression of the fifth cranial nerve in cases of trigeminal neuralgia effects its result by relieving pressure on an abnormally compressed nerve or by a non-specific effect of trauma. ${ }^{12}$ Partly fuelled by a lack of accurate information on the "normal" neurovascular anatomy, the reported incidence of vascular compression has ranged from $11 \%$ to $96 \%$ in clinical series and between $4 \%$ and $60 \%$ in normal post mortem examinations.

In this study operative conditions were simulated in age-matched fresh cadavers and the cerebral vessels perfused, in situ at physiological pressures during dissection. The findings in a total of 50 unilateral cadaver explorations were clearly different from those in 41 cases of trigeminal neuralgia which had prolonged follow-up. Whilst $10 \%$ of the clinical cases did not have significant vessel contact and pain recurred eventually in seven cases, gross distortion of the nerve by a vessel typified these cases. No significant compression was found in the post mortem studies with only light contact occurring in $11 \%$.

Thus whilst a debate as to the mechanism of action of "decompression" may continue and the aetiology of some cases remains in doubt, the results suggest neurovascular compression of the fifth cranial nerve to be an anatomical abnormality, specific to trigeminal neuralgia.

1 Jannetta PJ, Wilkins RH, Rengachary SS, eds. Neurosurgery, vol 3. New York: McGrawHill, 1985:2357-63.

2 Adams CBT. J Neurosurgery 1989;70:1-12.

SËLECTION FOR DORSAL COLUMN STIMULATION TO RELIEVE PAIN

J Miles. Liverpool

Dorsal column stimulation for the relief of persistent non-malignant pain has been used effectively for more than 20 years. However, all reports indicate that it does not relieve all forms of chronic benign pain. Each stimulator implant unit costs more than $£ 4000$. There is therefore a great need to attempt to select those patients likely to respond.'

Over the last 17 years a protocol has been used which permits an $80 \%$ response rate. After careful conventional, medical, neurological, psychological and pharmacological scrutiny, the protocol investigates the accessability of the pain to external influences, that is, to counter irritation, on the assumption that it is, at least in part, by this action that electrical stimulation has its effect.

More than 200 patients came into the study with chronic benign pain who were being considered for treatment by electrical stimulation. One hundred and seventy four patients had sufficient data to be analysed. Seventy eight were implanted with an electrical stimulator while 68 were rejected from this form of treatment. Thirty eight of those implanted had excellent pain relief, while 31 had only partial relief and usually this incompleteness of response could be predicted.

Percutaneous spinal cord stimulation was clearly the best predictor of eventual result. A hypertonic saline injection into the interspinus ligament was the next best test. Transcutaneous electrical stimulation (TNS), external heat, abrasion and the influence of weather were also helpful.

Spinal cord stimulation can relieve chronic pain over long periods. Selection of those most likely to respond is very necessary for clinical, psychological and financial reasons.

1 Miles JB. Ann Roy Coll Surg Eng 1983;66: 108-12.

THE TREATMENT OF MIDI.INE PERINEAL PAIN FOR CANCER

DE Kennemore. Greenville, South Carolina, USA

Midline perineal pain due to cancer is usually managed with narcotics. However, a few patients develop a severe and intractable pain that does not respond adequately to narcotic management. Neurosurgical procedures such as cordotomy, either percutaneous or open cordotomy have failed to relieve the pain in this position although the procedure may be performed bilaterally. Midline percutaneous radiofrequency spinal rhizotomy affecting the sacral nerve roots bilaterally has been effective in managing this problem without interfering with ambulation in seven patients with cancer of the rectum, colon, endometrium and one sacral cordoma. The procedure was performed in the radiography department as an outpatient procedure. The risks are minimal to the debilitated cancer patient.
Polish papers by title

INTRACRANIAL ANEURYSMS-EXPERIENCE WITH 910 TREATED PATIENTS A Marchel. Warsaw.

IMMUNOSUPPRESSIVE TREATMENT REDUCES THE NEUROLOGICAL DEFICIT AFTER EARLY CLIPPING OF RUPTURED ANEURYSM

M Pastuszko, M Ryba, J Bidzinski, $\mathrm{K}$ Iwanska, C Dziewiecki. Warsaw.

VALUE OF CT SCAN FOR PREDICTING HYPONATREMIA IN PATIENTS WITH RUPTURED INTRACRANIAL ANEURYSM

D Jaskolski, M Zawirski, J Jakuboswki. Lodz/Sheffield.

HLA GENES AND INTRACRANIAL ANEURYSMS P Grieb, M Ryba, I Podobinska, K Iwanska, M Pastuszko, A Gorski. Warsaw.

A COMBINED TRANSFRONTAL TRANSNASAL SURGERY FOR TUMOURS INVOLVING NASAL CAVITY AND ANTERIOR SKULL. BASE

F Tokarz, Z Pawlak. Poznan.

A ONE-STAGE COMBINED SURGERY FOR THE THIRD VENTRICLE TUMORS: PELLUCIDOTOMY BIOPSY AND VENTRICULOATRIAL SHUNT F Tokarz, S Nowak, A Kopras. Poznan.

FRONTO-ORBITAL APPROACH TO ANTERIOR CRANIAL FOSSA AND PARASELLAR LESIONS R Krajewski. Tripoli.

THE USEFULNESS OF MICROSONIC TECHNIC IN THE TREATMENT OF THE POSTERIOR CRANIAL FOSSA TUMORS IN CHILDREN

A Zycinski, J Ligarska, $M$ Wojtacha, J Baron. Katowice.

INTRAOPERATIVE ULTRASONOGRAPHY OF THE BRAIN TUMOURS

S Kaszynski, SZ Rudnicki, P Kozlowski. Warsaw.

INTRAOPERATIVE DIAGNOSTIC ULTRASOUND EXAMINATION OF THE CENTRAL NERVOUS SYSTEM

M Nowak, W Mazurowski, L Krolicki, M Zabek, G Janulis. Warsaw.

MODELLING OF ARTERIAL BLOOD PRESSUREINTRACRANIAL PRESSURE TRANSMISSION Czosnyka, Paluszek, Saworski, Laniewski, Batorski, Koszewski, Maksymowicz. Warsaw.

CONTINUOUS ANALYSIS AND CONTROL OF INTRACRANIAL PRESSURE

Czosnyka, Duda, Saworski, Laniewski, Batorski, Maksymowicz, Koszewski. Warsaw.

NONLINEAR EFFECT OF ICP ON CSF OUTFLOW RESISTANCE. AN EXPERIMENTAL APPROACH K Tychmanowicz, Z Czernicki, G Pawlowski, G Stepinska, J Jurkiewicz. Warsaw.

VARIABLE RATE INFUSION PROCEDURES IN EVALUATION OF THE INTRACRANIAL SYSTEM COMPENSATORY MECHANISMS G Pawlowski, S Sliwka. Warsaw.

THE ESTIMATION OF FUNCTIONING OF IMPLANTED SHUNT SYSTEM-THE ROLE OF CEREBROSPINAL COMPENSATORY PARAMETERS W Maksymowicz, M Czosnyka, W Koszewski, A Szymanska. Warsaw. 
THE PROBLEM OF THE LOCALISATION OF SOMATOMOTOR AREA IN EPILEPTIC PATIENTS BY SOMATOSENSORY EVOKED POTENTIALS J Bidzinski, E Szkiladz, T Bacia,

S Checinski. Warsaw.

SEP-MAPPING CORRELATION IN EPILEPTIC PATIENTS

E Purska-Rowinska, P Walerjan, E Mempel, R Tarnecki, D Horsztynski. Warsaw.

CRANIOPLASTY WITH A KNITED POLIPROPYLOPOLYESTER CODUBIX-FOLLOW-UP STUDY S Andrzejak, Z Kotwica, J Brzezioski. Lodz.

IMPROVEMENT OF MOTOR FUNCTION IN PARKINSON'S DISEASE AFTER

TRANSPLANTATION OF FETAL DOPAMINE NEURONS

W Mazurowski, M Zabek, B Gawur,

E Zawada. Warsaw.

ORIGINAL TECHNIC OF IMPLANTATION OF FETAL SUBSTANTIA NIGRA INTO CAUDATE NUCLEUS WITH PARKINSON'S DISEASE SUFFERING PATIENTS

M Zabek, W Mazurowski. Warsaw.
APPLICATION OF STATISTICAL ANALYSIS IN SPECIFYING THE PROGNOSIS OF PATIENTS, WITH TRAUMATIC INTRACRANIAL HEMATOMAS A Rudnik. Katowice.

ENCEPHALINS AND CEREBRAL BLOOD FLOW IN PATIENTS AFTER HEAD TRAUMA

Z Stachura, P Janas. Katowice.

SEVERITY OF HEAD INJURY ESTIMATED BY CSF OXIMETRY AND ENZYMATIC INDICES

R Zukiel, R Jankowski, F Tokarz. Poznaniu.

THE PROGNOSTIC VALUE OF SOME FACTORS IN HEAD INJURY IN CHILDREN

J Pajak, M Wojtacha. Katowice.

THE PROLONGED DEFICIENCY OF THE CSF OUTFLOW AS A FACTOR CONTRIBUTING TO THE UNSATISFACTORY OUTCOME FOLLOWING HEAD INJURY

L Kucinski, G Pawlowski, S Sliwka,

Z Czernicki, P Twarkowski. Warsaw.

NEUROSURGICAL PUBLICATIONS IN EUROPEAN JOURNALS

T'Trojanowski, I Rabow, L Rabow. Lublin Umea.
EXTRA-CRANIAI ARTERIAL ANASTOMOSIS AND OMENTAL TRANSPOSITION TO THE BRAIN AS THE COMPLEMENTARY METHODS OF TREATMENT OF CEREBRAL ISCHAEMIC DISEASE R Mrowska, J Pieniazek, S Hendryk,

A Dobkiewicz, W Szydlik. SzpitalGorniczy.

THE EFFECT OF MANNITOL ON ICP AND BRAIN WATER CONTENT IN NORMAL AND ISCHAEMIC BRAIN. NMR STUDY IN A RAT MODEL OF FOCAL ISCHEMIA

Z Kotwica, K-A Thuomas, L Persson.

Lodz/Uppsala.

RESULTS OF THE OPERATIVE TREATMENT OF CHILDREN WITH RUPTURED CEREBRAI ANEURYSM

A Bazowski, A Zycinski, J Pajak, J Gamrot, $M$ Wojtacha. Katowice. 